\title{
Electrodeposition of diamond-like carbon (DLC) films on $\mathrm{Ti}$
}

\author{
T.M. Manhabosco*, I.L. Muller \\ Laboratory of Corrosion Research, Metallurgy Department, Universidade Federal do Rio Grande do Sul, RS, Brazil
}

\section{A R T I C L E I N F O}

\section{Article history:}

Received 1 August 2008

Received in revised form 24 October 2008

Accepted 25 October 2008

Available online 6 November 2008

\section{PACS:}

81.15.Pq

81.05.UW

\section{Keywords:}

Electrodeposition

Diamond-like carbon

Organic liquids

\begin{abstract}
A B S T R A C T
Diamond-like carbon films (DLC) were deposited on titanium substrates in acetonitrile and N,N-dimethyl formamide (DMF) liquids by the liquid-phase electrodeposition technique at ambient pressure and temperature. The applied voltage between the electrodes was high $(1200 \mathrm{~V})$ due to the use of resistive organic liquids. The surface morphology was examined by Atomic Force Microscopy (AFM) and Scanning Electron Microscopy (SEM). Corrosion performance of the coatings was investigated by potentiodynamic polararization tests in phosphate buffer saline solution. Raman spectroscopy analysis of the films revealed two broad bands at approximately $1360 \mathrm{~cm}^{-1}$ and $1580 \mathrm{~cm}^{-1}$, related to D and G-band of DLC, respectively. The coated Ti was tested in a ball-on-plate type wear test machine with $\mathrm{Al}_{2} \mathrm{O}_{3}$ balls. The films presented a low friction coefficient (about 0.1), and the films deposited from DMF presented the best wear resistance.
\end{abstract}

(c) 2008 Elsevier B.V. All rights reserved.

\section{Introduction}

The implantation of a biomedical device into the human body allows it to reestablish mechanical and biological functions of the degenerated member making possible an increase in the life quality of the patient. Depending on the biomedical application, the device supports different mechanical loads being simultaneously exposed to the aggressive body environment, which requires materials with excellent corrosion and wear resistance, good hemocompatibility and mainly biocompatibility. Titanium and its alloys are extensively used in medical devices due the properties like good corrosion resistance and biocompatibility. However, due the host body reactions like inflammatory reactions and wear debris production in relative sliding, as on hip and knee joints, more resistant and advanced materials are required.

In the last decades, a lot of researchers have focused on the development of advanced biomaterials in order to supply the requirements of the human body. DLC (Diamond-like Carbon) films have been matter of intense research due to their interesting and well suitable properties like chemical inertness, high electrical resistance, optical transparency, high hardness, low friction

\footnotetext{
* Corresponding author at: Av. Bento Gonçalves 9500/Setor 4/Prédio 75/232, 91501-970 Porto Alegre, Rio Grande do Sul, Brazil. Tel.: +55 5133089406.

E-mail address: tmanhabosco@yahoo.com.br (T.M. Manhabosco).
}

coefficient, high wear resistance besides good bio and hemocompatibilities [1-7].

More commonly, the DLC films have been prepared by physical deposition techniques as Physical Vapor Deposition (PVD), Chemical Vapor Deposition (CVD), radio-frequency (RF), ion beam deposition and sputtering. Despite the high quality and growth rate of the films, sophisticated equipments with vacuum system and high temperature (usually higher than room temperature) are required. Recently (1992), an electrodeposition technique was used by Namba [8] aiming to prepare DLC films from an ethanol solution at $70^{\circ} \mathrm{C}$. However, the results indicated that DLC films were not achieved. Four years later, Wang et al. [9] presented the possibility to obtain DLC films from methanol solution. In subsequent studies other organic liquids, like acetonitrile, N,N-dimethyl formamide, formic acid, acetic acid, were used to obtain DLC films. As substrate for deposition, silicon and glass plate covered by ITO or SnO [9-13] are often used in the electrochemical deposition process. Following the same line of investigation on the electrodeposition of DLC films from a liquid phase, and considering that titanium and its alloys are of the most used materials for implants, the present work investigates the electrodeposition of DLC from organic liquids, acetonitrile and $\mathrm{N}, \mathrm{N}$-dimethyl formamide, directly onto titanium substrates at room temperature, aiming to increase the wear resistance of this material without deteriorating its good corrosion resistance. 


\section{Experimental details}

Pure titanium (Grade 1) disks of $9.51 \mathrm{~mm}$ diameter and $0.63 \mathrm{~mm}$ thick were ground with successively finer grit of $\mathrm{SiC}$ until 4000. The final polishing treatment was electropolishing in a solution composed of $60 \mathrm{ml} \mathrm{H}_{2} \mathrm{SO}_{4}, 30 \mathrm{ml} \mathrm{HF}$ and $10 \mathrm{ml}$ glycerin at a current density of $0.29 \mathrm{~A} / \mathrm{cm}^{2}$ for $2 \mathrm{~min}$. The solution temperature was controlled at $5-7{ }^{\circ} \mathrm{C}$. After the electropolishing, the samples were rinsed with bi-distilled water and placed for $1 \mathrm{~h}$ in ethanol to avoid the staining of the surface. Finally, the samples were cleaned and stored in a low vacuum environment.

The electrodeposition experiments were realized in a three electrode electrochemical cell with a water jacket in order to control the electrodeposition temperature at $25{ }^{\circ} \mathrm{C}$. The sample was placed in a Teflon holder $4 \mathrm{~mm}$ distant from the pure graphite counter electrode. An external thermometer was placed to verify the required temperature.

Two carbon sources were used for the electrodeposition process, acetonitrile and DMF. As the resistivities of these organic liquids are in the order of $10^{4}-10^{5} \Omega \mathrm{cm}$, a power source capable to apply more than a thousand volts was used. The electrodepositions at a potential of $1200 \mathrm{~V}$ were carried out for $4 \mathrm{~h}$ at $25^{\circ} \mathrm{C}$. An EG\&G Princeton Applied Research Model 273 potentiostat was used to obtain polarization curves in a PBS solution (phosphate buffer saline solution), composed of $8 \mathrm{~g} / 1$ $\mathrm{NaCl} ; 0.2 \mathrm{~g} / 1 \mathrm{KCl} ; 0.594 \mathrm{~g} / 1 \mathrm{Na}_{2} \mathrm{HPO}_{4}$ and $0.2 \mathrm{~g} / 1 \mathrm{KH}_{2} \mathrm{PO}_{4} ; \mathrm{pH}$ 7.1. The PBS solution and a temperature of $37{ }^{\circ} \mathrm{C}$ were used in order to simulate the physiologic environment. A saturated calomel electrode was used as a reference electrode and a platinum wire as counter electrode. Raman spectroscopy, one of the most used techniques to characterize diamond-like carbon films, was performed with a NTEGRA Spectra Nanofinder (NT-MDT) operating with a blue laser $(488 \mathrm{~nm})$ at room temperature. The wear tests were conducted with a ball-on-plate type wear test machine computationally controlled. The apparatus operates by rubbing a $5 \mathrm{~mm}$ diameter alumina ball (Saphirwerk) against the sample. Reciprocating wear tests were carried out with an applied force of $2 \mathrm{~N}$, velocity of $2 \mathrm{~mm} / \mathrm{s}$ and a linear wear track of $2 \mathrm{~mm}$. The wear tracks were examined with a surface profilometer (Microglider, Fries Research \& Technology). Six profile measurements were taken on each wear track, and with the measure of the track length the wear volume was computationally calculated. The wear tracks were also examined with an optical microscope. The morphology of titanium and of the obtained deposits were characterized by atomic force microscopy (AFM) and Scanning Electron Microscopy (SEM).

\section{Results and discussion}

For the film deposition the applied potential was rapidly increased from 0 to $1200 \mathrm{~V}$ and than kept constant for $4 \mathrm{~h}$. This high voltage is necessary to induce the pure organic molecules to polarize and react at the cathode forming the DLC films. The organic liquids are composed of polar molecules where the centers of the negative and the positive charge are not coincident. When high potentials are applied to this polar organic molecules $\left(\mathrm{M}-\mathrm{CH}_{3}\right.$ and $\left.\mathrm{M}-\left(\mathrm{CH}_{3}\right)_{2}\right)$, the distance between the centers becomes greater and the molecule becomes polarized $\left(\mathrm{M}^{\delta_{-}} \ldots . . . \mathrm{CH}_{3}{ }^{{ }^{++}}\right)$. The positive center moves to the cathode surface and when the energy is high enough, the bond between $\mathrm{M}^{\delta-}$ and $\mathrm{CH}_{3}{ }^{\delta+}$ would be broken and the $\mathrm{CH}_{3}{ }^{\delta+}$ center react on the cathode surface forming diamond-like carbon film and hydrogen gas. Sreejith et al. [11] deposited DLC films from methanol using lower voltages $(80-300 \mathrm{~V})$ by decreasing the electrode separation and so increasing the solution conductance, allowing larger current densities to flow. DLC films obtained at low potentials (under $5 \mathrm{~V}$ ) were presented by Gupta et al. $[14,15]$. The films were deposited onto $\mathrm{SnO}_{\mathrm{s}}$-coated glass from solutions composed of acetic acid $(0.5 \%$ and $1 \%, v / v)$ in water at $85{ }^{\circ} \mathrm{C}$. The authors propose a new deposition mechanism based on the acetic acid ionization in water forming $\mathrm{CH}_{3}{ }^{+}$and $\mathrm{H}^{+}$positive radicals that would be anchored at oxygen-deficient sites of $\mathrm{SnO}_{2}$ substrate.

The current transients for the samples deposited at $1200 \mathrm{~V}$ on titanium substrate both from acetonitrile and DMF are shown in Fig. 1, respectively. The current densities developed in $5 \mathrm{~s}$ of deposition for different potentials are also shown. As presented, the current densities increase with applied potential as expected for organic liquid, which require high potentials to polarize.

During the film deposition from acetonitrile, the current density decreases from $0.9 \mathrm{~mA} / \mathrm{cm}^{2}$ to $0.1 \mathrm{~mA} / \mathrm{cm}^{2}$ in approximately $120 \mathrm{~min}$ and then remains constant indicating that the growth rate saturates with time. This is also reported by other authors $[10,11,13]$, even for low potential deposition $[14,15]$, and should be related to the high film resistivity after a monolayer deposition, because the true solid-liquid interface is not anymore a titaniumorganic liquid interface but a DLC film-organic liquid interface. In the first 25 min of the film deposition from DMF, it occurs also a decrease in the current density, which then turns to increase reaching at $16 \mathrm{~mA} / \mathrm{cm}^{2}$. As the deposition proceeds and the current density increases, gas evolution is observed on the cathode. According to the proposed deposition mechanism and by the explosive reaction of the formed gas with oxygen, it is inferred that the gas is hydrogen. The gas evolution was also observed by other authors $[16,17]$, however they do not present the increase in the current density for deposition from DMF. This occurrence could be
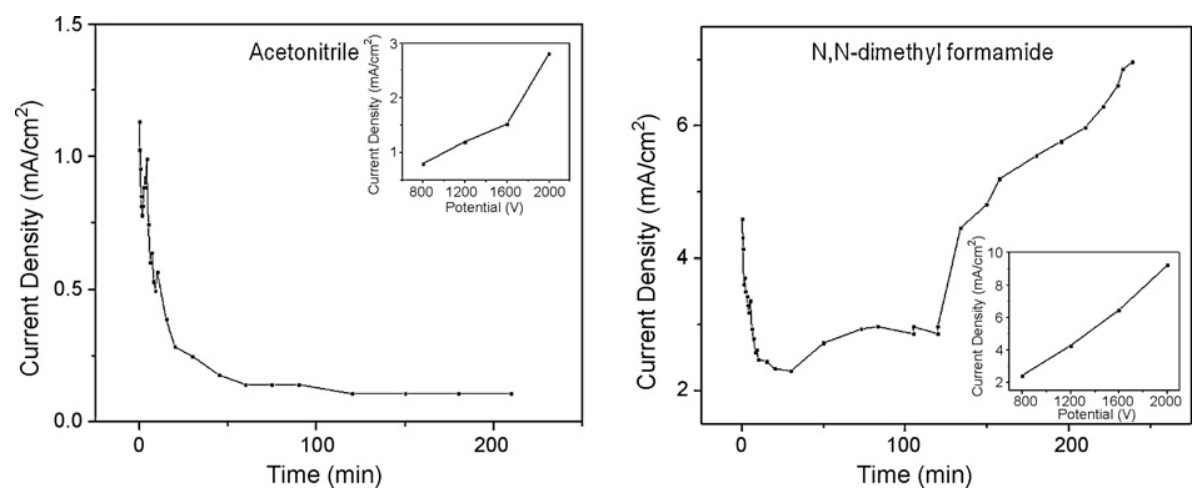

Fig. 1. Current transients for film deposition from acetonitrile and DMF at $1200 \mathrm{~V}$ and $25^{\circ} \mathrm{C}$. Insets present $I-V$ characteristics for film deposition. 
(a)

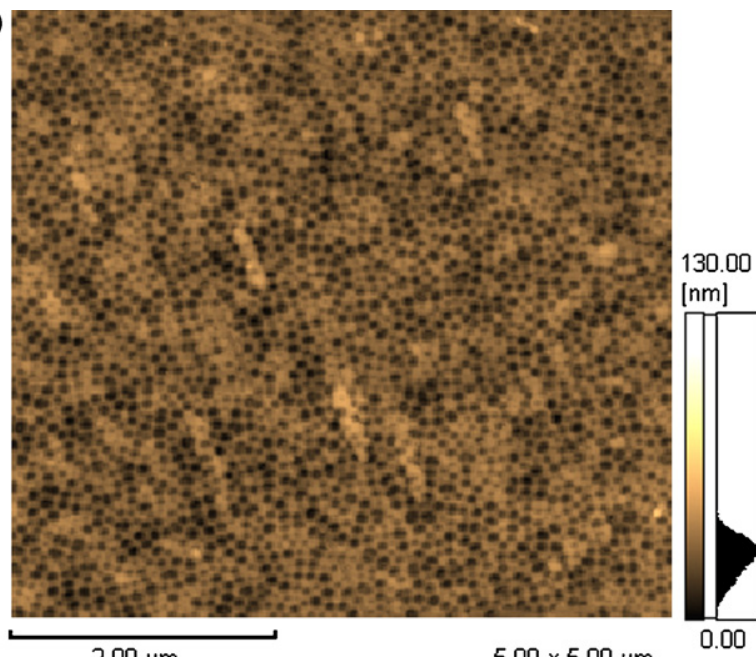

(b)

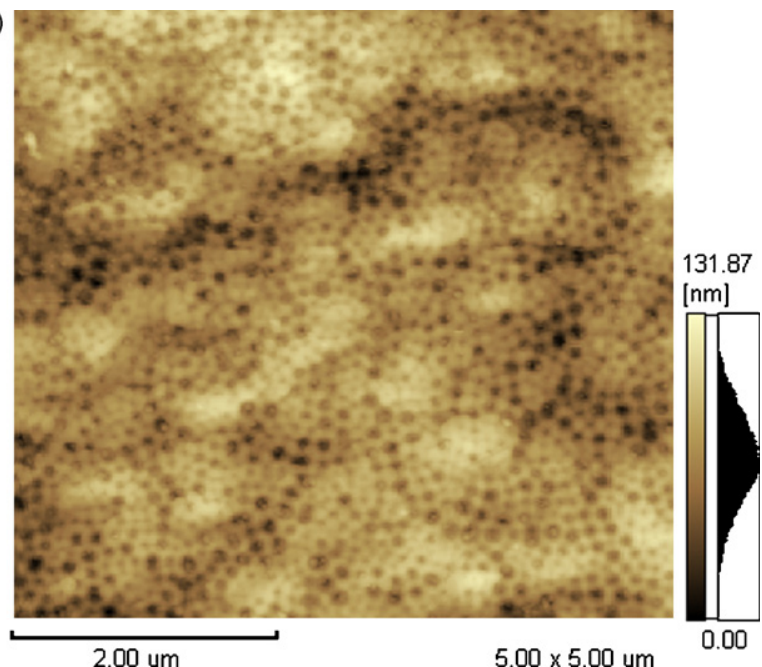

Fig. 2. Two-dimensional AFM images for electropolished titanium (a) and DLC film obtained from DMF (b).

related to differences in the deposition apparatus or in the substrate material, as they play an important role in the electrodeposition process $[18,19]$.

Fig. 2 shows AFM top views of the electropolished titanium sample (a) and the DLC film obtained from DMF (b). It is observed that the titanium surface, electropolished in a solution containing $\mathrm{H}_{2} \mathrm{SO}_{4}$, HF and glycerin, presents an interesting structure corresponding to a porous oxide resulting from the electropolishing process. When the titanium sample is mechanically finished the structure presented in Fig. 2 is not observed. The DLC thin films obtained both from DMF and acetonitrile (this one not shown), present a similar morphology that copies the substrate morphology, so as it occurs for other systems in electrodeposition processes $[20,21]$. Three-dimensional DLC film images show that the films surface is regular and smooth, with an rms (root mean square) roughness of about $50 \mathrm{~nm}$, what is well suitable for surfaces exposed to sliding contact. Cao et al. [13] deposited DLC films from different organic liquids (DMF, acetonitrile, methanol and ethanol) onto ITO-coated glasses and obtained films composed of small and compact balls. Also, Yan et al. [7] obtained films composed of small and compact spheres from methanol onto silicon. By comparison it is possible to confirm that the substrate structure plays an important role on film morphology.

Bare and DLC covered titanium corrosion resistance was evaluated by potentiodynamic polarization in PBS solution and the results are presented in Fig. 3. As it can be seen, the DLC films obtained from DMF did not increase the corrosion resistance if compared to the pure titanium. This behaviour may be related to very small cracks in the film as observed in the SEM image (Fig. 4) and to some uncovered substrate areas, since gas evolution was observed during the deposition process. The films obtained from acetonitrile, on the contrary present a nobler open-circuit potential, around $0.1 \mathrm{~V}$, and lower anodic current density until $0.9 \mathrm{~V}$. These results point to the interest in proceeding with the investigation of new conditions trying to improve the properties of the electrodeposited DLC films.

The Raman spectrum of the films deposited from acetonitrile and DMF were deconvoluted using a Gaussian and a Lorentzian line shape in order to obtain the $I_{\mathrm{D}} / I_{\mathrm{G}}$ ratio, a qualitative indicator of the bond nature and of the graphitization degree. With the Gaussian line shape it was obtained a better curve fit. The Gaussian deconvoluted spectra (Fig. 5) for films obtained from DMF reveal two peaks located around $1360 \mathrm{~cm}^{-1}$ and $1580 \mathrm{~cm}^{-1}$, which can be related to the $\mathrm{D}$ and $\mathrm{G}$ bands, typical for diamond-like carbon films.
The $\mathrm{G}$ band is assigned to $\mathrm{sp}^{2}$ trigonal bonding (graphite phase), while the D band is attributed to the "disordered carbon", i.e., the bond-angle disorder in the $\mathrm{sp}^{2}$ graphite-like microdomains, induced by the linking with $\mathrm{sp}^{3} \mathrm{C}$ atoms, as well as the finite

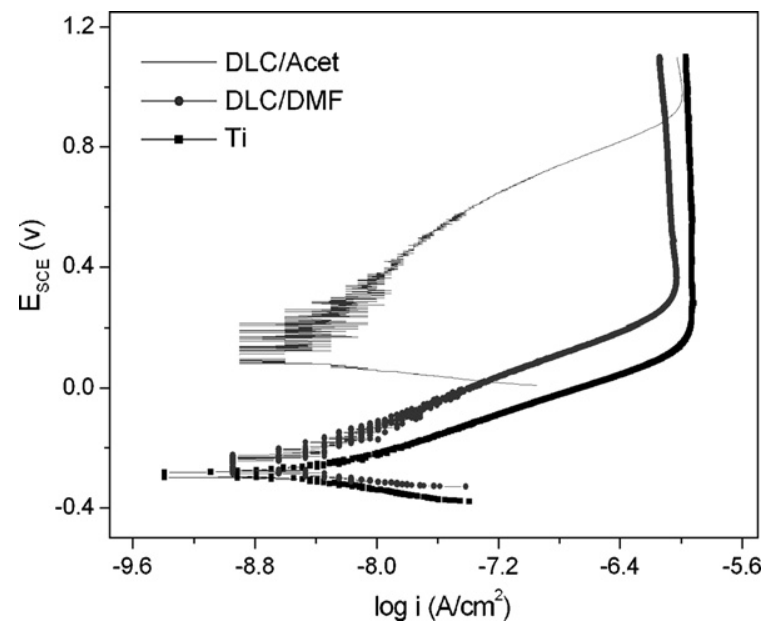

Fig. 3. Potentiodynamic polarization in PBS solution ( $\mathrm{pH} 7.1$ ) for Ti covered with DLC films obtained from acetonitrile and DMF and for Ti substrate. Sweep rate: $0.166 \mathrm{mV} / \mathrm{s}$.

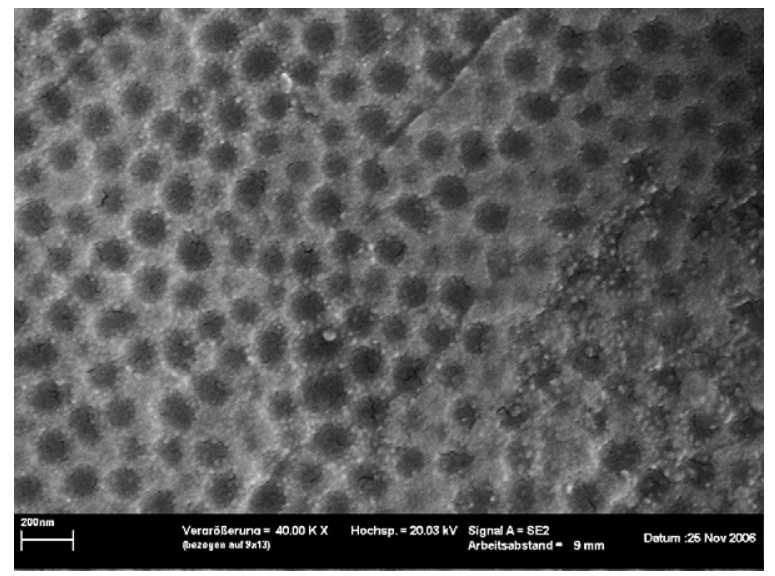

Fig. 4. SEM image of DLC film electrodeposited from DMF onto titanium. 


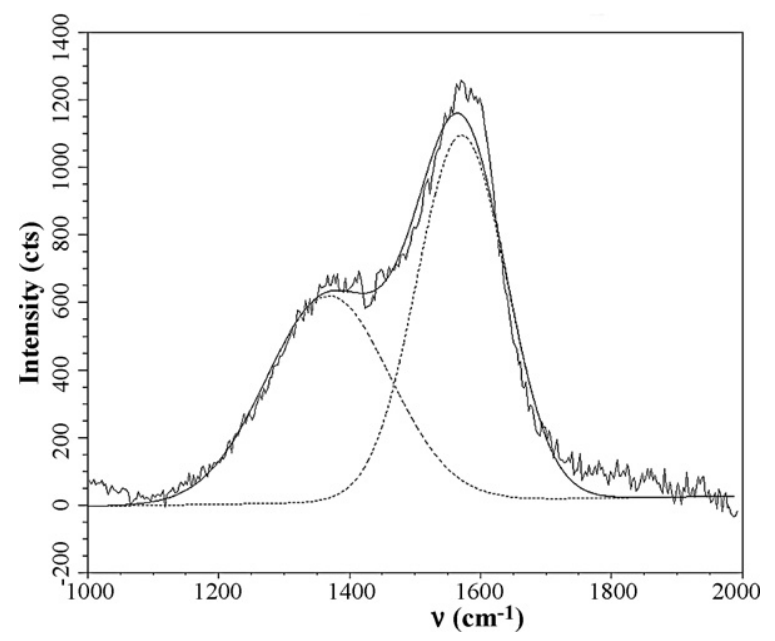

Fig. 5. Raman deconvoluted spectra for DLC films obtained from DMF.

Table 1

Raman results for films obtained from acetonitrile and DMF.

\begin{tabular}{lll}
\hline Organic liquid & G band position $\left(\mathrm{cm}^{-1}\right)$ & $I_{\mathrm{D}} / I_{\mathrm{G}}$ ratio \\
\hline Acetonitrile & 1577 & 1.05 \\
DMF & 1573 & 0.83 \\
\hline
\end{tabular}

crystalline sizes of $\mathrm{sp}^{2}$ microdomains [22]. The $I_{\mathrm{D}} / I_{\mathrm{G}}$ ratio as well as the $\mathrm{G}$ band position is presented in Table 1. Beeman et al. [23] built well acceptable computer models for amorphous carbon and according to their theory model, a shift in the $G$ band position toward lower wave numbers is ascribed to an increase in the $\mathrm{sp}^{3}$ content. An increase in $\mathrm{I}_{\mathrm{D}} / \mathrm{I}_{\mathrm{G}}$ ratio is correlated with an increase in the graphite-like nano-crystallites [22,24,25]; however, the literature is ambiguous and presents also contrary results that report an increase in $\mathrm{I}_{\mathrm{D}} / \mathrm{I}_{\mathrm{G}}$ ratio as the $\mathrm{sp}^{3}$ content increases $[13,26]$. Taking in consideration the well accepted Beeman model, the DLC films obtained from DMF present higher $\mathrm{sp}^{3}$ content, as they present lower $I_{\mathrm{D}} / I_{\mathrm{G}}$ ratio.

Fig. 6 shows the variations of the friction coefficient with the sliding time for DLC films and for titanium substrate. The data were acquired from the wear tests realized with an alumina ball sliding against the sample at an applied force of $2 \mathrm{~N}$. As it is expected, the

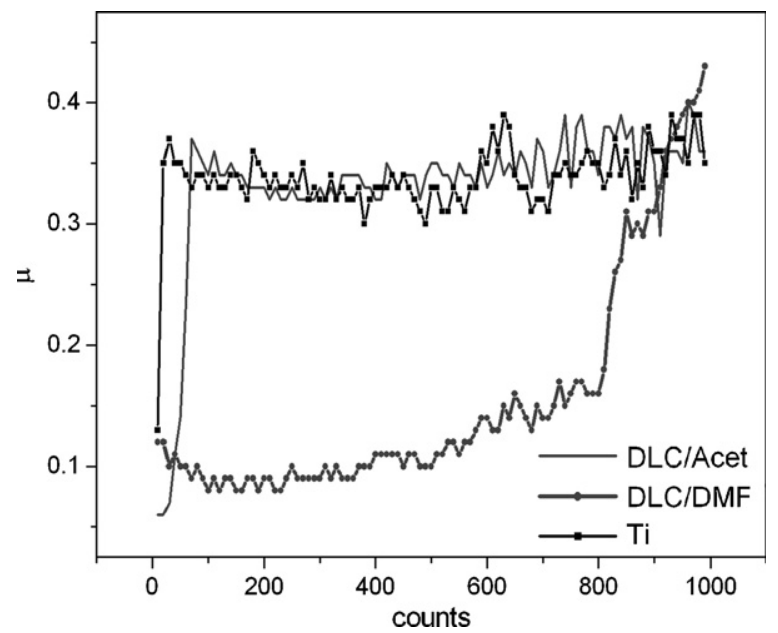

Fig. 6. Friction coefficients determined in wear tests for DLC-covered $\mathrm{Ti}$ and $\mathrm{Ti}$ substrate. Applied force $2 \mathrm{~N}$, wear velocity $2 \mathrm{~mm} / \mathrm{s}$, track length $2 \mathrm{~mm}$.

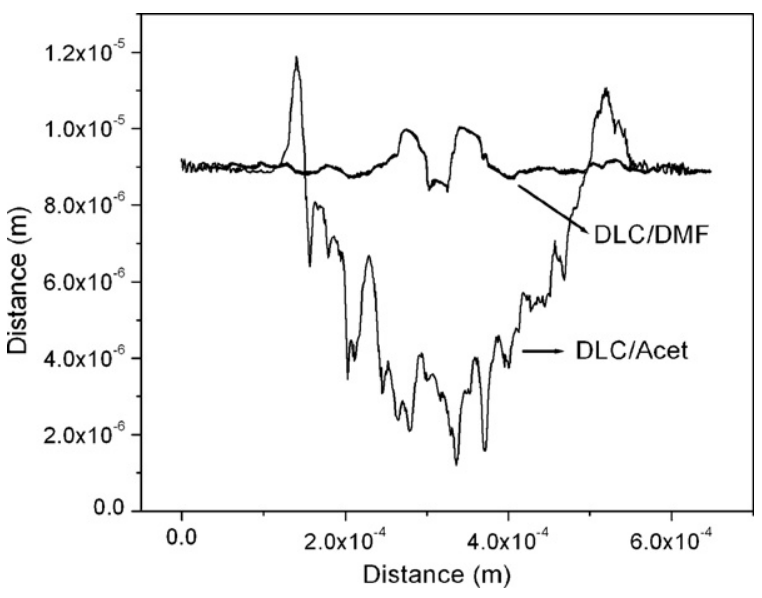

Fig. 7. Wear track profile for Ti covered with DLC-films obtained from acetonitrile and DMF. Applied force $2 \mathrm{~N}$, wear velocity $2 \mathrm{~mm} / \mathrm{s}$, track length $2 \mathrm{~mm}$.

DLC films show a low friction coefficient around $0.1[3,4,6]$. As the thickness of the films is very small and the normal force is high, if compared with tests realized on similar electrodeposited films $[7,27]$, they are rapidly removed exposing the titanium substrate, as verified by a fast increase on the friction coefficient.

The thickness of the films obtained from DMF during $4 \mathrm{~h}$, was evaluated to be between 58 and $80 \mathrm{~nm}$, by laser profilometry. The thickness of the films obtained from acetonitrile was also tried to measure, however it could not be evaluated because the resolution of the equipment was about $40 \mathrm{~nm}$. So the thickness is estimated as being less than $40 \mathrm{~nm}$. The current transients, the wear tests results and microscopy observation, support that the films deposited from acetonitrile are thinner than that deposited from DMF.

After the wear test, the wear tracks were analyzed by optical microscopy and their profiles acquired by a profilometer. Fig. 7 shows the profile of the wear tracks for films obtained from acetonitrile and DMF. The wear volume for DLC obtained from acetonitrile is similar to the wear volume for pure titanium, about $3 \times 10^{-9} \mathrm{~m}^{3}$. The wear volume for DLC obtained from DMF is reduced by 20 times indicating a superior wear resistance. These differences in the wear volume presented by the films obtained from two different sources of carbon can be mainly related to film thickness.

An interesting morphology is presented by DLC films obtained from DMF, not only on a nanoscale but also at a microscale observed by light microscope. As also observed by AFM, the DLC film copies and reveals the titanium substrate microstructure. The wear track, as showed by profilometry, is narrow with the film ploughed off in specific sites but without significant deformation of the substrate on the boarders of the track. A low amount of wear debris was observed. On the other hand, the wear track for the samples deposited from acetonitrile presents some smeared titanium base material and some irregular plastic deformation of the metal around the sliding ball path as was also presented in the wear track for pure titanium. The small thickness of the film in this case transfers the force to the ductile substrate promoting its deformation in addition to the wear of the film.

\section{Conclusions}

The present work shows the possibility to obtain DLC films directly on titanium substrate by the electrodeposition technique operating at room temperature. 
The films obtained from acetonitrile and DMF were characterized as DLC, with D and G bands, by Raman spectra. Films obtained from DMF present a lower $I_{\mathrm{D}} / I_{\mathrm{G}}$ ratio and a shift in the $G$ band position toward lower wave numbers than those obtained from acetonitrile.

A superior corrosion resistance was presented by films obtained from acetonitrile, however the wear resistance of the substrate was not improved. A corrosion resistance similar to bare titanium, a superior wear resistance and a low friction coefficient were presented by DLC films obtained from DMF. The low wear resistance for the films obtained from acetonitrile can be related to the extremely small thickness of the deposits and the corrosion behaviour of the films obtained from DMF can be related to the presence of cracks and some uncovered areas.

\section{Acknowledgments}

The authors are thankful to the Brazilian government agencies CAPES and CNPQ for supporting the present research and to the Institute Fraunhofer (Stuttgart-Germany) for allowing the Raman measurements and wear tests.

\section{References}

[1] F.Z. Cui, D.J. Li, Surf. Coat. Technol. 131 (2000) 481.
[2] R. Hauert, Diamond Relat. Mater. 12 (2003) 583.

[3] L. Huang, J. Lu, K. Xu, Thin Solid Films 466 (2004) 175.

[4] A.-S. Loir, F. Garrelie, C. Donnet, J.-L. Subtil, M. Belin, B. Forest, F. Rogemond, P. Laporte, Appl. Surf. Sci. 247 (2005) 225

[5] R. Hauert, Tribol. Int. 37 (2004) 991.

[6] A. Erdemir, O.L. Eryilmaz, G. Fenske, J. Vac. Sci. Technol. A 18 (2000 1987).

[7] X.B. Yan, T. Xu, S.R. Yang, H.W. Liu, Q.J. Xue, J. Phys. D: Appl. Phys. 37 (2004) 2416.

[8] Y. Namba, J. Vac. Sci. Technol. A 10 (1992) 3368.

[9] H. Wang, M.-R. Shen, Z.-Y. Ning, C. Ye, C.-B. Cao, H.-Y. Dang, H.-S. Zhu, Appl. Phys. Lett. 69 (1996 1074)

[10] Q. Fu, J.T. Jiu, C.B. Cao, H. Wang, H.S. Zhu, Surf. Coat. Technol. 124 (2000) 196.

[11] K. Sreejith, J. Nuwad, C.G.S. Pillai, Appl. Surf. Sci. 252 (2005) 296.

[12] J.T. Jiu, K. Cai, Q. Fu, C.B. Cao, H.S. Zhu, Mater. Lett. 41 (1999) 63.

[13] C. Cao, H. Zhu, H. Wang, Thin Solid Films 368 (2000) 203.

[14] S. Gupta, R.K. Roy, B. Deb, S. Kundu, A.K. Pal, Mater. Lett. 57 (2003) 3479.

[15] S. Gupta, M.P. Chowdhury, A.K. Pal, Appl. Surf. Sci. 236 (2004) 426.

[16] W.L. He, R. Yu, H. Wang, H. Yan, Carbon 43 (2005) 2000.

[17] M. Roy, A.K. Dua, A.K. Satpati, Diamond Relat. Mater. 14 (2005) 60.

[18] D. Guo, K. Cai, L.-t. Li, Y. Huang, Z.-l. Gui, H.-S. Zhu, Carbon 39 (2001) 1395.

[19] K. Cai, D. Guo, Y. Huang, H.-S. Zhu, Appl. Phys. A 71 (2000) 227.

[20] A. Reitzle, F.U. Renner, T.L. Lee, J. Zegenhagen, D.M. Kolb, Surf. Sci. 576 (2005) 19

[21] M.V. Rastei, R. Meckenstock, E. Devaux, Th. Ebbesen, J.P. Bucher, J. Magn. Magn. Mater. 286 (2005) 10

[22] R.O. Dillon, J.A. Woollam, V. Katkanant, Phys. Rev. B 29 (1984) 3482.

[23] D. Beeman, J. Silverman, R. Lynds, M.R. Anderson, Phys. Rev. B 30 (1984) 870.

[24] S. Prawer, K.W. Nugent, Y. Lifshitz, G.D. Lempert, E. Grossman, J. Kulik, I. Avigal, R. Kalish, Diamond Relat. Mater. 5 (1996) 433.

[25] G. Messina, A. Paoletti, S. Santangelo, A. Tebano, A. Tucciarone, Microsys. Technol. 26 (1999) 30.

[26] T.W. Scharf, H. Deng, J.A. Barnard, J. Appl. Phys. 81 (1997) 5393.

[27] X. Yan, T. Xu, G. Chen, S. Yang, H. Liu, Appl. Surf. Sci. 236 (2004) 328. 